\title{
PENGARUH KEPEMIMPINAN, INSENTIF DAN \\ LINGKUNGAN KERJA TERHADAP LOYALITAS \\ KARYAWAN ADMINISTRATIF KANTOR FAKULTAS DI \\ UNIVERSITAS AHMAD DAHLAN YOGYAKARTA
}

\author{
Huda Khoyrun \\ hudama92@gmail.com \\ Universitas Ahmad Dahlan \\ Utik Bidayati \\ utik.bidayati@yahoo.com \\ Universitas Ahmad Dahlan
}

\begin{abstract}
ABSTRAK
This study aims to determine the effect of leadership, incentives and work environment both partially and jointly on the loyalty of the administrative staff of the Faculty office at Ahmad Dahlan University, Yogyakarta. This research is a quantitative research. Data collection using a questionnaire method (questionnaire) that has been tested for validity and reliability, while data analysis is done using multiple linear regression analysis. The sample of this study was all administrative employees in all faculties at Ahmad Dahlan University, amounting to 60 employees with sample collection techniques using saturated samples, so the sample size in this study amounted to 60 employees. The results showed that: 1) Leadership has a significant effect on employee loyalty, this is indicated by the results of the test of 3.123 with a significance of 0.003 . 2) Incentives have a negative and significant effect on employee loyalty, this is indicated by the results of t count of $-2,378$ with a significance of 0.021. 3) The work environment has no effect on employee loyalty. 4) Leadership, incentives and work environment together have a significant effect on employee loyalty, this is indicated by an $\mathrm{F}$ count of 3.647 with a significance of 0.0 .018 with a regression equation $\mathrm{Y}=-2.315+$ $0.432 \mathrm{X} 1-0.333 \mathrm{X} 2+0.099 \mathrm{X} 3+\mathrm{e}$. With a large effect of $0.16 .3 \%$, while the remaining $83.7 \%$ is influenced by other independent variables that are not observed.
\end{abstract}

Keywords: Leadership; Incentive; Work environment; Loyalty.

\section{PENDAHULUAN}

Pada saat ini perkembangan di dunia pendidikan sangat pesat terutama di tingkat perguruan tinggi. Semakin baiknya kondisi perekonomian Indonesia merupakan salah satu faktor yang mempengaruhi perkembangan di dunia pendidikan. Banyak universitas yang berusaha untuk meningkatkan kualitasnya guna menghadapi persaingan yang semakin kompetitif. Salah satu cara yang dilakukan yaitu dengan memperbaiki dan mengembangkan kualitas sumber daya manusia yang dimilikinya. Dengan memiliki sumber daya manusia yang unggul diharapkan dapat meningkatkan kualitas dari perguruan tinggi tersebut. Maka dari itu perlu adanya loyalitas dari karyawan untuk ikut terlibat dalam meningkatkan dan mengembangkan kualitas dan daya saing perguruan tinggi. Universitas Ahmad Dahlan (UAD) merupakan salah satu perguruan tinggi swasta yang berada di provinsi Yogyakarta. Dalam perkembangan di dunia pendidikan yang sangat kompetitif Universitas Ahmad Dahlan (UAD) dituntut untuk mempunyai sumber daya manusia yang unggul dan memiliki loyalitas yang tinggi guna bersaing di dunia pendidikan. 
Loyalitas karyawan sangat dituntut dalam organisasi atau perusahaan manapun karena semakin tinggi loyalitas karyawan maka akan semakin total kinerja yang diberikan sebaliknya karyawan yang memiliki loyalitas yang rendah maka akan memberi kinerja yang rendah pada organisasi atau perusahaan. Untuk meningkatkan loyalitas sumber daya manusia banyak faktor yang dapat mempengaruhinya.

Menurut Mangkunegara, (2005) dalam Sapaynarta dan Dewi (2013) Secara teoritis faktor-faktor yang dapat mempengaruhi loyalitas sangat banyak seperti gaya kepemimpinan, produktivitas kerja, pemenuhan harapan penggajian dan insentif, jenis pekerjaan, struktur organisasi, kesempatan promosi, hubungan kerja, dan lingkungan kerja. Richard S dan Coughlan dalam jurnalnya (2005), Loyalitas adalah tindak etis seorang karyawan dalam melakukan pekerjaan dan dalam membina hubungan dengan rekan kerja. Karyawan yang loyal sangat dihargai oleh perusahaan karena perusahaan sangat membutuhkan karyawan-karyawan yang loyal untuk kelangsungan organisasi atau perusahaan dalam menentukan maju mundurnya organisasi atau perusahaan di masa mendatang.

Martoyo (2007) dalam Astuti (2014) Kepemimpinan adalah keseluruhan aktivitas dalam rangka mempengaruhi orang-orang agar mau bekerja sama untuk mencapai suatu tujuan yang memang diinginkan bersama. Kepemimpina merupakan faktor yang sangat penting dalam mempengaruhi prestasi suatu organisasi karena kepemimpinan merupakan aktivitas yang utama dimana tujuan organisasi dapat dicapai. Selain kepemimpinan pemberian insentif merupakan salah satu bentuk motivasi yang penting diberikan karena dapat meningkatkan gairah kerja karyawan sehingga dapat menimbulkan loyalitas kerja karyawan yang kemudian dapat mencapai hasil yang dikehendaki organisasi atau perusahaan.

Peningkatan loyalitas karyawan memberikan dampak positif dalam pencapaian tujuan organisasi atau perusahaan, oleh sebab itu manajemen harus mempelajari sikap dan prilaku para karyawannya dalam perusahaan tersebut. Menurut Riani (2013) dalam Dahlan, Lisbeth Mananeke dan Lucky O.H Dotulong (2014) insentif adalah sarana untuk memotifasi karyawan dalam mencapai suatu target tertentu. Selama ratusan tahun, pegawai menerima sejumlah uang untuk output yang telah ditentukan

\section{Rumusan Masalah}

1. Apakah ada pengaruh insentif terhadap loyalitas karyawan Administratif Kantor Fakultas di Universitas Ahmad Dahlan Yogyakarta?

2. Apakah ada pengaruh kepemimpinan, terhadap loyalitas karyawan Administratif Kantor Fakultas di Universitas Ahmad Dahlan Yogyakarta ?

3. Apakah ada pengaruh lingkungan kerja terhadap loyalitas karyawan Administratif Kantor Fakultas di Universitas Ahmad Dahlan Yogyakarta ?

4. Apakah ada pengaruh insentif, kepemimpinan dan lingkungan kerja terhadap loyalitas karyawan Administrasi Kantor Fakultas di Universitas Ahmad Dahlan Yogyakarta ?

\section{REVIEW LITERATUR DAN HIPOTESIS}

\section{Landasan Teori \\ Kepemimpinan}

Kepemimpinan adalah suatu bentuk proses mempengaruhi dan prilaku untuk memenangkan hati, pikiran, dan tingkah laku orang lain (Muhith dan Setiawan, 2013:). Sedangkan menurut Martoyo (2007) dalam Astuti (2014) 
kepemimpinan adalah keseluruhan aktivitas dalam rangka mempengaruhi orangorang agar mau bekerja sama untuk mencapai suatu tujuan yang memang diinginkan bersama.

\section{Inisiatif}

Menurut Hasibuan (2011) dalam Ratnasari, Raharjo dan Makzam (2013) Insentif adalah tambahan balas jasa yang diberikan kepada karyawan tertentu yang prestasinya di atas prestasi standar. Menurut Riani (2013) dalam Dahlan, Mananeke dan Dotulong (2014) insentif adalah sarana untuk memotifasi karyawan dalam mencapai suatu target tertentu.

\section{Loyalitas}

Loyalitas adalah tindak etis seorang karyawan dalam melakukan pekerjaan dan dalam membina hubungan dengan rekan kerja, (Richard dan Coughlan dalam jurnalnya, 2005). Secara teoritis faktorfaktor yang dapat mempengaruhi loyalitas sangat banyak seperti gaya kepemimpinan, produktivitas kerja, pemenuhan harapan penggajian dan insentif, jenis pekerjaan, struktur organisasi, kesempatan promosi, hubungan kerja, dan lingkungan kerja (Mangkunegara, 2005) dalam (Sapaynarta dan Dewi, 2013).

\section{Penelitian Terdahulu}

1. Menurut Dwipayoga (2013) dalam penelitiannya yang berjudul "Pengaruh Lingkungan Kerja Fisik, Kepemimpinan, dan Kompensasi Terhadap Loyalitas Pada PT. Gino Falentino", hasil penelitian menunjukan bahwa: variabel lingkungan kerja fisik, kepemimpinan, dan kompensasi berpengaruh positif dan signifikan secara simultan terhadap loyalitas kerja karyawan PT. Gino Valentino Bali. Variabel lingkungan kerja fisik, kepemimpinan, dan kompensasi

berpengaruh positif dan signifikan secara parsial terhadap loyalitas kerja karyawan PT. Gino Valentino Bali. Dari ketiga variabel bebas tersebut yaitu variabel lingkungan kerja fisik, kepemimpinan, dan kompensasi yang dominan mempengaruhi loyalitas kerja karyawan pada PT. Gino Valentino Bali adalah variabel Kompensasi.

2. Menurut Ratnasari, Dwi, Raharjo, dan Makzam (2013), dalam penelitian yang berjudul "Pengaruh Insentif Terhadap Loyalitas Karyawan PT SIER (Persero) Surabaya", menyimpulkan bahwa variabel insentif materil (X1) secara parsial mempunyai pengaruh positif dan signifikan terhadap loyalitas karyawan (Y).

3. Menurut Sapaynarta dan Dewi (2013), dalam penelitian yang berjudul "Pengaruh Insentif Finansial dan lingkungan kerja fisik terhadap loyalitas karyawan PT JASARAHARJA PUTERA CABANG DENPASAR", hasil penelitian menunjukan bahwa secara parsial variabel insentif finansial (X1) berpengaruh positif dan signifikan terhadap loyalitas karyawan, sedangkan lingkungan kerja fisik (X2) berpengaruh positif dan signifikan terhadap loyalitas karyawan.

\section{Hipotesis}

H1: Terdapat pengaruh kepemimpinan terhadap loyalitas karyawan bagian administratif kantor Fakultas Universitas Ahmad Dahlan

$\mathrm{H} 2$ : Terdapat pengaruh insentif terhadap loyalitas karyawan bagian administratif kantor Fakultas Universitas Ahmad Dahlan.

H3: Terdapat pengaruh lingkungan kerja terhadap loyalitas karyawan bagian administratif kantor Fakultas Universitas Ahmad Dahlan.

H4: Terdapat pengaruh kepemimpinan, insentif, dan lingkungan kerja terhadap loyalitas karyawan bagian administratif kantor Fakultas Universitas Ahmad Dahlan. 


\section{METODE PENELITIAN}

\section{Populasi dan Sampel}

Menurut Sugiyono (2014:119) populasi adalah wilayah generalisasi yang terdiri atas: objek/subjek yang mempunyai kualitas dan karakteristik tertentu yang ditetapkan oleh peneliti untuk dipelajari, dan kemudian ditarik kesimpulannya. Jadi populasi bukan hanya orang, tetapi juga objek dan bendabenda alam ini. Populasi juga bukan sekedar jumlah yang ada pada objek/subjek yang dipelajari, tetapi meliputi seluruh karakteristik/ sifat yang dimiliki oleh subjek atau objek itu.

Menurut Sugiyono (2014:120) sampel adalah bagian dari jumlah dan karakteristik yang dimiliki oleh populasi tersebut. Bila populasi besar, dan peneliti tidak mungkin mempelajari semua yang ada pada populasi, misalnya karena keterbatasan dana, tenaga dan waktu, maka peneliti dapat menggunakan sempel yang diambil dari populasi itu. Apa yang dipelajari dari sampel itu, kesimpulannya akan dapat diberlakukan untuk populasi. Untuk itu sampel yang diambil dari polupasi harus betul-betul representatif (mewakili). Sampel dalam penelitian ini berjumlah 60 karyawan administratif kantor fakultas.

\section{Definisi Operasional}

1. Variabel Independen

Variabel independen : variabel ini sering disebut variabel stimulus, prekdiktor, antecedent. Dalam bahasa Indonesia sering disebut dengan variabel bebas. Variabel bebas adalah merupakan variabel yang mempengaruhi atau yang menjadi sebab perubahannya atau timbulnya variabel dependen(terkait). Dalam penelitian ini yang menjadi variabel independen (bebas) adalah kepemimpinan, insentif, dan lingkungan kerja yang meliputi:

$\begin{array}{ll}\text { X1 } & =\text { Kepemimpinan } \\ \text { X2 } & =\text { Insentif } \\ \text { X3 } & =\text { Lingkungan Kerja }\end{array}$

2. Variabel Dependen

Variabel Dependen : sering disebut sebagai variabel output, kriteria, konsekuen. Dalam bahasa Indonesia sering disebut sebagai variabel terkait. Variabel terkait merupakan variabel yang dipengaruhi atau yang menjadi akibat, karena adanya variabel bebas. Dalam penelitian ini yang merupakan variabel dependen adalah kinerja karyawan (Y)

\section{Uji Instrumen}

1. Uji Validitas

Uji Validitas Menurut Sujarweni (2007:99), uji validitas digunakan untuk mengetahui kelayakan butir-butir dalam suatu daftar pertanyaan dalam mendefinisikan suatu variabel. Daftar pertanyaan ini pada umumnya mendukung suatu kelompok variabel tertentu.

Uji validitas dilakukan pada setiap butir pernyataan. Hasil r.hitung dibandingkan dengan r.tabel (lihat di tabel $\mathrm{r}$, dimana $\mathrm{df}=\mathrm{n}-2 \quad$ (sig $5 \%$, njumlah sempel).

\section{Uji Reliabilitas}

Menurut Sujarweni (2007:99), uji reabilitas (keandalan) merupakan ukuran suatu kestabilan dan konsistensi responden dalam menjawab hal yang berkaitan dengan kontruk-kontruk pertanyaan yang merupakan dimensi suatu variabel dan disusun dalam suatu bentuk kuesioner. Uji reliabilitas dapat dilakukan secara bersama-sama terhadap seluruh butir pertanyaan. Jika nilai Cronbach Alpha > 0,60 maka reliabel

Jika nilai Cronbach Alpha < 0,60 maka tidak reliabel 


\section{Teknik Analisis Data}

1. Analisis Regresi Berganda

Menurut Sujarweni (2007:81), untuk mengetahui besarnya pengaruh perubahan dari satu variabel terhadap variabel lainnya, yaitu variabel kepemimpinan (X1), insentif (X2), dan lingkungan kerja (X3), terhadap loyalitas karyawan $(\mathrm{Y})$ dengan rumus:

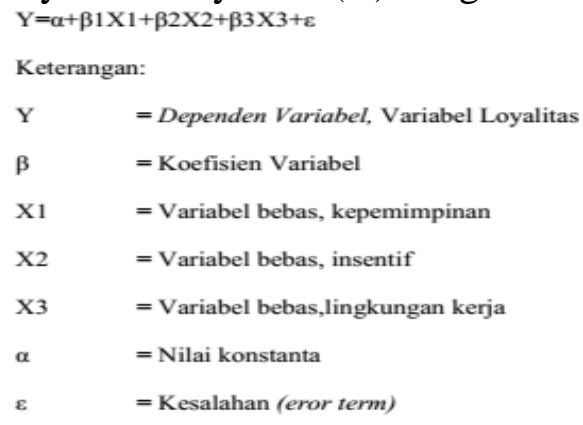

\section{Uji Hipotesis}

\section{Uji Parsial (Uji T)}

Menurut Purwanto (2004:523), untuk melihat apakah variabel secara parsial berpengaruh nyata tidak digunakan $\mathrm{Uji}-\mathrm{t}$ atau $t$-student. a) $\mathrm{HO}=0$ Artinya: tidak ada pengaruh antara variabel independen kepemimpinan, insentif, dan lingkungan kerja secara parsial terhadap variabel dependen loyalitas karyawan. $\mathrm{Ha} \neq 0$ Artinya: ada pengaruh antara variabel independen kepemimpinan, insentif, dan lingkungan kerja secara parsial terhadap variabel dependen loyalitas karyawan.

\section{Uji Simultan (Uji F)}

Menurut Purwanto (2004:523), untuk melihat apakah variabel bebas mampu secara menyeluruh bersamasama menjelaskan tingkah laku variabel tidak bebas, untuk pengujian ini dikenal dengan Uji Global atau Uji F.

a) $\mathrm{HO}=0$ Artinya: tidak ada pengaruh secara serempak dari semua variabel independen kepemimpinan, insentif dan lingkungan kerja terhadap variabel dependen loyalitas karyawan.

$\mathrm{Ha} \neq 0$ Artinya: ada pengaruh secara serempak dari semua variabel independen kepemimpinan, insentif, dan lingkungan kerja terhadap variabel dependen loyalitas karyawan.

\section{Uji Koefisien Determinasi}

Koefisien determinasi digunakan untuk mengetahui seberapa besar variabilitas variabel-variabel independen mampu memperjelas variabilitas variabel dependen. Koefisien determinasi pada regresi logistik dapat dilihat pada nilai nagelkerke R Square. Nilai nagelkerke $\mathrm{R}$ Square dapat dienterpretasikan seperti nilai R Square pada regresi berganda, Ghozali (2006) dalam http://elib.unikom.ac.id/. Kecocokan model akan baik jika R2 semakin besar atau semakin mendekati nilai 1 perhitungan SPSS.

Batas nilai $\mathrm{R}_{2}$ adalah $0-1$. Apabila $\mathrm{R}_{2}=1$, berarti besarnya pengaruh variabel $\mathrm{X}$ terhadap variabel $\mathrm{Y}$ sebesar $100 \%$. Tetapi bila $\mathrm{R}_{2}=0$, berarti tidak ada pengaruh dari variabel $\mathrm{X}$ terhadap variabel Y.

\section{HASIL PENELITIAN DAN PEMBAHASAN}

\section{Hasil Analisis Responden}

Penelitian ini dilakukan di seluruh kantor fakultas yang ada di Universitas Ahmad Dahlan Yogyakarta. Peneliti menyebar kuesioner dengan terlebih dahulu meminta surat izin penelitian ke Dekan Fakultas Ekonomi kemudian peneliti melakukan survei ke bagian Sumber Daya Manusia (SDM). Setelah peneliti mendapatkan izin dari bagian Sumber Daya Manusia (SDM), kemudian peneliti menghitung jumlah responden yang akan dijadikan sampel penelitian. Setelah menentukan jumlah responden yang akan diteliti kemudian peneliti meminta surat izin 
untuk melakukan penelitian dari Dekan Fakultas Ekonomi, yang kemudian surat di berikan kepada Wakil Rektor 2 untuk meminta persetujuan dari Wakil Rektor 2. Peneliti membutuhkan waktu selama satu Minggu untuk mendapat surat resmi agar penelitian bisa dilaksanakan.

\section{Hasil Penelitian}

1. Hasil Uji Validitas

a. Kepemimpinan

1) Pengujian pertama

Tabel 5.2

Component Matriks

\begin{tabular}{|c|c|c|}
\hline \multirow{2}{*}{ Permyataan } & \multicolumn{2}{|c|}{ Component } \\
\cline { 2 - 3 } & 1 & 2 \\
\hline A1 & .300 & .687 \\
\hline A2 & .712 & -.262 \\
\hline A3 & .804 & -.107 \\
\hline A4 & .592 & .402 \\
\hline A5 & .725 & -.380 \\
\hline A6 & .855 & -.262 \\
\hline
\end{tabular}

2) Pengujian Kedua

Tabel. 5.3

Komponen Matriks

\begin{tabular}{|c|c|c|}
\hline \multirow{2}{*}{ Pernyataan } & \multicolumn{2}{|c|}{ Component Matriks } \\
\cline { 2 - 3 } & 1 & 2 \\
\hline A1 & .310 & .752 \\
\hline A3 & .748 & -.021 \\
\hline A4 & .641 & .308 \\
\hline A5 & .714 & -.424 \\
\hline A6 & .847 & -.312 \\
\hline A7 & .813 & -.198 \\
\hline A8 & .681 & .459 \\
\hline
\end{tabular}

3) Pengujian Ketiga

Tabel. 5.4

Komponen Matriks

\begin{tabular}{|c|c|}
\hline \multirow{2}{*}{ Pernyataan } & Component \\
\cline { 2 - 2 } & 1 \\
\hline A3 & .743 \\
\hline A4 & .639 \\
\hline A5 & .737 \\
\hline A6 & .857 \\
\hline A7 & .823 \\
\hline A8 & .660 \\
\hline
\end{tabular}

Tabel di atas menunjukan butirbutir pernyataan yang valid diantaranya, A3, A4, A5, A6, A7, dan A8, sedangkan A1, dan A2 merupakan data yang tidak valid, dan dinyatakan gugur. Pernyataan yang telah valid akan diajukan kepada responden yang tersisa sebanyak 30 responden, namun didalamnya tidak terdapat pernyataan yang mewakili dari indikator, mengarahkan kelompok untuk mencapai tujuan karena kedua pernyataan yang mewakili indikator, mengarahkan kelompok untuk mencapai tujuan telah gugur dalam pengujian validitas yaitu A1 dan A2.

b. Inisiatif

Tabel 5.5

Komponent Matriks

\begin{tabular}{|c|c|}
\hline \multirow{2}{*}{ Pernyataan } & Component \\
\cline { 2 - 2 } & 1 \\
\hline B1 & .747 \\
\hline B2 & .700 \\
\hline B3 & .813 \\
\hline B4 & .782 \\
\hline B5 & .792 \\
\hline B7 & .622 \\
\hline
\end{tabular}

Sumber : Data primer, diolah 2015

Tabel di atas menunjukan butirbutir pernyataan yang valid diantaranya, B1, B2, B3, B4, B5, dan B7, sedangkan B6 merupakan data yang tidak valid dan dinyatakan gugur. Pernyataan yang telah valid akan di ajukan kepada responden yang tersisa sebanyak 30 responden. 
c. Lingkungan Kerja

Tabel 5.6

Component Matriks

\begin{tabular}{|c|c|}
\hline \multirow{2}{*}{ Pernyataan } & Component \\
\cline { 2 - 2 } & 1 \\
\hline $\mathrm{C} 1$ & .739 \\
\hline $\mathrm{C} 2$ & .747 \\
\hline $\mathrm{C} 4$ & .843 \\
\hline $\mathrm{C} 5$ & .732 \\
\hline \multicolumn{2}{|c|}{} \\
\hline \multicolumn{2}{|c|}{ Sumber : Data primer, diolah 2015 }
\end{tabular}

Tabel di atas menunjukan butir butir pernyataan yang valid diantaranya, $\mathrm{C} 1$, C2, C4 dan B7, sedangkan C3, C6, C7, C8, C9 dan C10 merupakan data yang tidak valid dan dinyatakan gugur. Pernyataan yang telah valid akan diajukan kepada responden yang tersisa sebanyak 30 responden, namun didalamnya tidak pernyataan yang mewaklili dari indikator perlengkapan kerja dan hubungan personal karena ke empat pernyataan yang mewakili indikator perlengkapan kerja dan hubungan personal telah gugur dalan pengujian validitas yaitu $\mathrm{C} 6, \mathrm{C} 8$, C9 dan C10.

d. Loyalitas

Tabel 5.7

Component Matriks

\begin{tabular}{|c|c|}
\hline \multirow{2}{*}{ Pernyataan } & Component \\
\cline { 2 - 2 } & 1 \\
\hline D1 & .754 \\
\hline D3 & .539 \\
\hline D5 & .875 \\
\hline D7 & .822 \\
\hline D8 & .674 \\
\hline D9 & .750 \\
\hline
\end{tabular}

Tabel di atas menunjukan butir-butir pernyataan yang valid diantaranya, D1, D3, D5, D7, D8, dan, D9 sedangkan D2, D4, D6 dan D10 merupakan data yang tidak valid dan dinyatakan gugur. Pernyataan yang telah valid akan diajukan kepada responden, namun didalamnya tidak terdapat pernyataan yang mewakili indikator bersedia bekerja lembur untuk menyelesaikan pekerjaan dan menjaga rahasia organisasi karena keempat pernyataan pernyataan yang mewakili indikator tersebut telah gugur yaitu D2, D4, D6 dan D10.

2. Hasil Uji Reliabilitas

1) Variabel Kepemimpinan

Tabel 5.8

\begin{tabular}{|c|r|c|c|}
\hline Pernyataan & $\begin{array}{c}\text { Cronbach } \\
\text { Alpha ( } \alpha)\end{array}$ & $\begin{array}{c}\text { Alpha } \\
\text { (Konstruk) }\end{array}$ & Keputusan \\
\hline P3 & 0.813 & 0,60 & Reliabel \\
\hline P4 & 0.830 & 0,60 & Reliabel \\
\hline P5 & 0.816 & 0,60 & Reliabel \\
\hline P6 & 0.786 & 0,60 & Reliabel \\
\hline P7 & 0.791 & 0,60 & Reliabel \\
\hline P8 & 0.830 & 0,60 & Reliabel \\
\hline
\end{tabular}

2) Variabel insentif

Tabel 5.9

\begin{tabular}{|l|r|r|r|}
\hline Pernyataan & $\begin{array}{r}\text { Cronbach } \\
\text { Alpha (a) }\end{array}$ & $\begin{array}{r}\text { Alpha } \\
\text { (Konstruk) }\end{array}$ & \\
\hline P1 & 0.765 & 0,60 & Reliabel \\
\hline P2 & 0.786 & 0,60 & Reliabel \\
\hline P3 & 0.727 & 0,60 & Reliabel \\
\hline P4 & 0.765 & 0,60 & Reliabel \\
\hline P5 & 0.766 & 0,60 & Reliabel \\
\hline P7 & 0.816 & 0,60 & Reliabel \\
\hline \multicolumn{4}{|r|}{ Sumber : Data primer, diolah 2015 } \\
\hline
\end{tabular}

3) Variabel lingkungan kerja

Tabel 5.10

\begin{tabular}{|l|r|r|r|}
\hline Pernyataan & $\begin{array}{r}\text { Cronbach } \\
\text { Alpha (a) }\end{array}$ & $\begin{array}{r}\text { Alpha } \\
\text { (Konstruk) }\end{array}$ & Keputusan \\
\hline P1 & 0.751 & 0,60 & Reliabel \\
\hline P2 & 0.687 & 0,60 & Reliabel \\
\hline P4 & 0.644 & 0,60 & Reliabel \\
\hline P5 & 0.728 & 0,60 & Reliabel \\
\hline
\end{tabular}

Sumber : Data primer, diolah 2015 
4) Variabel Loyalitas

Tabel 5.11

\begin{tabular}{|l|r|r|r|}
\hline Pernyataan & $\begin{array}{r}\text { Cronbach } \\
\text { Alpha (a) }\end{array}$ & $\begin{array}{r}\text { Alpha } \\
\text { (Konstruk) }\end{array}$ & \\
\hline P1 & .878 & 0,60 & Reliabel \\
\hline P3 & .912 & 0,60 & Reliabel \\
\hline P5 & .847 & 0,60 & Reliabel \\
\hline P7 & .863 & 0,60 & Reliabel \\
\hline P8 & .900 & 0,60 & Reliabel \\
\hline P9 & .886 & 0,60 & Reliabel \\
\hline
\end{tabular}

Berdasarkan ringkasan hasil uji reliabilitas diatas, maka dapat diketahui nilai koefisien Cronbach Alpha $(\alpha)$ pada masing-masing pernyataan di setiap variabel > 0,60 sehingga dapat disimpulkan bahwa semua pernyataan dalam penelitian ini adalah reliabel dan dapat digunakan untuk penelitian selanjutnya.

\section{Hasil Uji Regresi Linier Berganda}

Tabel 5.12

\begin{tabular}{|l|r|r|r|}
\hline \multicolumn{1}{|c|}{ Variabel } & \multicolumn{1}{|c|}{ Koefisien } & t Test & \multicolumn{1}{c|}{ Sign. } \\
\hline \multicolumn{1}{|c|}{ Konstanta } & $-2.315 \mathrm{E}-16$ & .000 & 1.000 \\
\hline Kepemimpinan & .432 & 3.123 & .003 \\
\hline Insentif & -.339 & -2.378 & .021 \\
\hline Lingkungan kerja & .099 & .783 & .437 \\
\hline F Test & $3.647 \rightarrow$ sign. 0,018 \\
\hline R Square & 0,163 \\
\hline
\end{tabular}

2. $\mathrm{Y}=-2.135 \mathrm{e}-16+0,432 X_{1}-0,339 X_{2}+0,099 X_{3}+\mathrm{e}$

1). Variabel Motivasi

Yang memliki nilai koefisien = 0.432 yang berarti kenaikan variabel 1 tingkat, maka loyalitas karyawan akan naik 0.432 dengan asumsi variabel yang tetap.

2). Variabel Disiplin

Yang memilki arti nilai koefisien $=$ -0,339 yang berarti kenaikan 1 tingkat, maka loyalitas karyawan akan naik dengan asusmsi nlai variabel $-0,339$ dengan asumsi variabel yanmg tetap.

3). Variabel Partisipasi

Yang memiliki nilai koefisien = 0.009 yang berarti kenaikan variabel 1 tingkat, maka loyalitas karyawan akan naik 0.009 dengan asumsi variabel tetap.

\section{Hasil Uji Parsial (Uji T)}

Hal ini juga dapat dilihat dari nilai sign. hitung $=0,003<$ alpha $(\alpha)=$ 0,05 yang berarti bahwa kepemimpinan berpengaruh terhadap loyalitas karyawan administratif Fakultas di Universitas Ahmad Dahlan atau terima Ha1

Hal ini juga dapat dilihat dari nilai sign. hitung $=0,021<$ alpha $(\alpha)$ $=0,05$ yang berarti bahwa insentif berpengaruh terhadap loyalitas karyawan administratif Fakultas di Universitas Ahmad Dahlan atau terima $\mathrm{Ha} 2$.

Hal ini juga dapat dilihat dari nilai sign. hitung $=0,437>$ alpha $(\alpha)=$ 0,05 yang berarti bahwa lingkungan kerja tidak berpengaruh terhadap loyalitas karyawan administratif Fakultas di Universitas Ahmad Dahlan atau terima Ha3.

Hal ini juga dapat dilihat dari nilai sign. hitung $=0,018<$ alpha $(\alpha)=$ 0,05 yang berarti kepemimpinan, insentif dan lingkungan kerja secara bersama-sama berpengaruh terhadap loyalitas karyawan administratif Fakultas di Universitas Ahmad Dahlan atau terima Ha4.

\section{Hasil Uji Koefisien Determinasi}

Dari perhitungan menggunakan komputer menunjukan bahwa koefisien determinasi (R2) mempunyai nilai sebesar 0,163. Hal ini berarti bahwa $16,3 \%$ dari loyalitas karyawan administratif seluruh Fakultas di Universitas Ahmad Dahlan dapat dijelaskan oleh variabel kepemimpinan, insentif dan lingkungan kerja sebagai variabel bebas, sedangkan sisanya sebanyak $83,7 \%$ dari variabel terikat (loyalitas karyawan) diterangkan oleh variabel bebas lain yang tidak diteliti. 
Pembahasan

(X1)

berpengaruh

signifikan

terhadap Loyalitas

Karyawan

Administratif di kantor Fakultas Universitas Ahmad Dahlan. Pada variabel Kepemimpinan (X1) memiliki koefisien regresi sebesar 0,432 yang berarti jika pemimpin memiliki kecakapan, mengarahkan kelompok untuk mencapai tujuan, mengkoordinasikan kelompok, mempengaruhi orang-orang dalam kelompok dan mengetahui kekuatan dan kelemahan dalam dirinya sebesar satu satuan maka akan meningkatkan loyalitas sebesar 0,432. Hasil penelitian ini sesuai dengan penelitian Dwipayoga (2013) yang menyatakan bahwa Kepemimpinan berpengaruh signifikan terhadap Loyalitas Karyawan PT. Gino Valentino Bali. Kepemimpinan dari seorang pemimpin Administratif di kantor Fakultas di Universitas Ahmad Dahlan Yogyakarta masih harus diperbaiki terutama dalam hal mengarahkan kelompok untuk mencapai tujuan organisasi, karena jika pemimpin mampu mengarahkan karyawan untuk mencapai tujuan organisasi maka akan mempercepat untuk tercapainya tujuan organisasi dan akan membuat organisasi menjadi lebih baik. Memiliki kecakapan, mengkoordinasikan kelompok, mempengaruhi orang-orang dalam kelompok serta mengetahui kelemahan dan kekuatan masih harus ditingkatkan oleh Pemimpin Staf Administrasi di kantor Fakultas Universitas Ahmad Dahlan. Ketika pemimpin mampu menujukan kepemimpinan yang baik maka dapat meningkatkan Loyalitas Karyawan Administratif di kantor Fakultas Universitas Ahmad Dahlan Yogyakarta. Berdasarkan hasil pengujian menunjukkan bahwa Insentif (X2) berpengaruh negatif dan signifikan terhadap Loyalitas karyawan administratif di kantor Fakultas Universitas Ahmad Dahlan. Pada variabel
Insentif (X2) memiliki nilai koefisien sebesar -0,339 yang berarti jika insentif naik sebesar satu satuan maka loyalitas akan turun sebesar 0,339. Hasil penelitian ini kurang sesuai dengan penelitian Ratnasari $d k k$ (2013), yang menyatakan bahwa variabel insentif berpengaruh positif dan signifikan terhadap loyalitas karyawan. Insentif yang di ukur dengan bonus dan komisi memiliki pengaruh negatif dan signifikan, walaupun berpengaruh tetapi tidak meningkatkan loyalitas karyawan Administratif di kantor Fakultas Universitas Ahmad Dahlan Yogyakarta. Ada kemungkinan hal ini disebabkan karna insentif bukan satusatunya ukuran yang dapat meningkatkan Loyalitas karyawan. Ada banyak hal lain yang dapat mempengaruhi loyalitas karyawan, dalam hal ini selain insentif ada beberapa orang yang bekerja karna hobi atau nyaman dengan kondisi kerja sehingga kurang memperhatikan insentif tersebut.

Berdasarkan hasil pengujian menunjukkan bahwa Lingkungan Kerja (X3) tidak berpengaruh terhadap Loyalitas Karyawan di kantor Fakultas Universitas Ahmad Dahlan. Pada variabel Lingkungan Kerja (X3) memiliki nilai koefisien sebesar 0,099 yang berarti jika variabel Lingkungan Kerja naik satu satuan maka akan meningkatkan loyalitas sebesar 0,009. Hasil penelitian ini kurang sesuai dengan penelitian Sapaynarta dan Dewi (2013), yang menunjukan bahwa variabel lingkungan kerja berpengaruh positif dan signifikan terhadap loyalitas karyawan PT. Jasaraharja Cabang Denpasar. Meskipun Lingkungan Kerja tidak berpengaruh tetapi harus tetap diperhatikan dan ditingkatkan dari segala hal terutama dalam peralatan kerja yang belum mendukung sepenuhnya aktivitas karyawan dan hubungan komunikasi antar karyawan harus 
ditingkatkan demi terjalinnya kerjasama yang baik antar karyawan. Pelayanan kepada pegawai yang diberikan belum memenuhi keinginan pegawai sehingga perlu adanya perbaikan dan kondisi kerja pun harus ditingkatkan oleh setiap Fakultas demi menunjang aktivitas kerja para pegawai. Lingkungan Kerja yang baik diharapkan mampu meningkatkan loyalitas karyawan kepada organisasinya, dengan tingkat loyalitas yang semakin baik diharapkan mampu mempercepat dalam pencapaian tujuan organisasi tersebut. Untuk variabel kepemimpinan (X1), insentif (X2) dan lingkungan kerja (X3) secara bersama-sama berpengaruh signifikan terhadap loyalitas karyawan Administratif Fakultas di Universitas Ahmad Dahlan Yogyakarta. Pengaruh yang timbul adalah positif yaitu semakin baik kepemimpinan, insentif dan lingkungan kerja akan semakin tinggi pula tingkat loyalitas karyawan administratif kantor Fakultas di Universitas Ahmad Dahlan Yogyakarta.

Banyak faktor yang mempengaruhi loyalitas karyawan administratif, kepemimpinan, insentif dan lingkungan kerja secara bersamasama menyumbang $16,3 \%$ dalam penentuan apakah seorang karyawan memiliki loyalitas yang tinggi atau rendah terhadap organisasinya. Dari hasil analisis didapat bahwa Kepemimpinan dari pimpinan di setiap Fakultas bagian Administratif harus lebih meningkatkan pengarahan kelompok dalam pencapaian tujuan di masing-masing Fakultas. Selain itu pemimpin juga harus memperhatikan kecakapan dalam berinteraksi dengan bawahannya, mengkoordinasikan kelompok dalam tugas yang telah ditetapkan, dan harus bisa mempengaruhi orang-orang dalam kelompok untuk selalu lebih baik, serta mengetahui kekuatan dan kelemahan didalam organisasinya terutama yang berhubungan dengan bawahannya. Insentif harus diperhatikan oleh Fakultas terutama dalam hal bonus dan komisi, dikarnakan ketika insentif yang diberikan tidak mencukupi kebutuhan dan keinginan karyawan maka akan menurunkan loyalitas karyawan. Lingkungan kerja juga harus diperhatikan serta ditingkatkan oleh Fakultas terutama dalam hal perlengkapan kerja, peralatan kerja dan kondisi ruang selain itu hubungan personal juga harus di ciptakan sebaik mungkin oleh karyawan agar tercipta loyalitas yang lebih baik bagi organisasi.

\section{KESIMPULAN DAN SARAN}

\section{Kesimpulan}

Penelitian ini bertujuan untuk menganalisis pengaruh Kepemimpinan, Insentif dan Lingkungan Kerja terhadap Loyalitas Karyawan Administratif Kantor Fakultas Di Universitas Ahmad Dahlan Yogyakarta. Sampel yang digunakan sebanyak 60 karyawan seluruh Fakultas Universitas Ahmad Dahlan Yogyakarta.

Berdasarkan hasil penelitian dan analisis data, maka peneliti mengambil kesimpulan sebagai berikut:

1. Kepemimpinan berpengaruh signifikan terhadap Loyalitas Karyawan Administratif Kantor Fakultas Di Universitas Ahmad Dahlan Yogyakarta. Hal tersebut ditunjukkan dari hasil Uji t hitung sebesar 3,123 dengan signifikansi $\quad 0,003$.

2. Insentif berpengaruh signifikan terhadap Loyalitas Karyawan Administratif Kantor Fakultas Di Universitas Ahmad Dahlan Yogyakarta. Hal tersebut ditunjukkan dari hasil Uji $\mathrm{t}$ hitung sebesar -2,378 dengan signifikansi 0,021. 
3. Lingkungan Kerja tidak berpengaruh terhadap Loyalitas Karyawan Administratif Kantor Fakultas Di Universitas Ahmad Dahlan Yogyakarta. Hal tersebut ditunjukkan dari hasil Uji $\mathrm{t}$ hitung sebesar 0,783 dengan ignifikansi 0,437.

4. Kepemimpinan, Insentif dan Lingkungan Kerja secara bersama-sama berpengaruh signifikan terhadap Loyalitas Karyawan Administratif Kantor Fakultas Di Universitas Ahmad Dahlan Yogyakarta. Hal tersebut ditunjukkan dari hasil Uji t hitung sebesar 3,674 dengan signifikansi 0,018. Kemampuan model variabel independen yaitu Kepemimpinan, nsentif dan Lingkungan Kerja dalam menerangkan variasi variabel dependen yaitu Loyalitas Karyawan sebesar $16,3 \%$ sedangkan $83,7 \%$ dijelaskan dan di terangkan oleh variabel bebas lain yang tidak diamati

\section{Saran}

Dengan melihat kesimpulan dan keterbatasan peneliti diatas, maka peneliti memberikan saran-saran sebagai berikut:

1. Bagi Universitas Ahmad Dahlan :

a. Meskipun variabel Lingkungan Kerja tidak berpengaruh terhadap Loyalitas Karyawan Administratif Kantor Fakultas di Universitas Ahmad Dahlan. Sebaiknya Fakultas tetap lebih meningkatkan kondisi Lingkungan Kerja karyawan sebab pada kondisi tertentu variable tersebut dapat mempunyai pengaruh terhadap loyalitas karyawan fakultas di Universitas Ahmad Dahlan.

b. Variabel Kepemimpinan dan Insentif berpengaruh terhadap Loyalitas Karyawan Administratif Kantor Fakultas di Universitas Amad Dahlan. Maka peneliti menyarankan agar Fakultas selalu meningkatkan dan memperhatikan aspek Kepemimpinan dan Insentif karyawannya agar karyawan dapat memenuhi target yang diinginkan93 Universitas terpenuhi dan mempunyai loyalitas tinggi dan kedisiplinan serta partisipasi yang baik.

2. Bagi Peneliti Mendatang :

Peneliti di masa yang akan datang sebaiknya memperluas variabel independen penelitian terutama mengenai indikator-indikatornya. Variabel Lingkungan Kerja lebih memperhatikan objek dan indikator penelitian.

Variabel Insentif lebih diperluas lagi, serta memperhatikan objek penelitian mengenai perbedaan insentif di organisasi dan perusahaan, serta indikator yang digunakan dalam penelitian harus di perjelas. Kuesioner yang digunakan sebaiknya lebih memperjelas indikator yang digunakan, dan variabel insentif lebih digali lagi mengenai instrumennya sehingga tingkat Loyalitas karyawan Administratif Kantor Fakultas di Universitas Ahmad Dahlan Yogyakarta dapat lebih baik lagi.

\section{DAFTAR PUSTAKA}

Adhila, Fitroh, Dyah Fitriani, dan Deny Ismanto. 2013. Modul Praktikum Statistik 2. Yogyakarta : Fakultas Ekonomi Universitas Ahmad Dahlan.

Alghifari. 2003. Statistika Induktif untuk Ekonomi dan Bisnis, edisi 2. Yogyakarta. AMP YKPN

Astuti. 2014. Pengaruh Kepemimpinan, Motifasi, Budaya Organisasi Dan Lingkungan Kerja Terhadap Kinerja Karyawan Pada Perusahaan Batik 
Mekar Yogyakarta. Skripsi. Yogyakarta. Fakultas Ekonomi Universitas Ahmad Dahlan

Dahlan, Mohammad Y, Lisabeth Mananeke dan Lucky O.H Dotulong.2014. Pelaksanaan Program Kesehatan Dan Keselamatan Kerja Serta Pemberian Insentif Terhadap Kinerja Karyawan UD. Sinar Sakti Malalayang. Jurnal Ekonomi Dan Bisnis, Vol.2 No.2 Juni 2014. Universitas Sam Ratulangi Manado

Djula, Badriyah. 2013. Pengaruh Pemberian Insentif Terhadap Prestasi Kerja Karyawan. Jurnal. Fakultas Ekonomi UNG

Dwiprayoga, Kadek Suhendra Wina dan I.G.A Dewi Adnyani. 2013. Pengaruh Lingkungan Kerja Fisik,Kepemimpinan, dan Kompensasi Terhadap Karyawan PT. Gino Valentino Bali. Jurnal. Bali. Fakultas Ekonomi Universitas Udayana.

Hidayah, Nurul. 2011. Pengaruh Pemberian Kompensasi dan Lingkungan Kerja Terhadap Kepuasan Kerja Karyawan Bagian Produksi PT. Madu Baru Yogyakarta. Skripsi. Yogyakarta. Universitas Ahmad Dahlan.

Martoyo, Susilo. 2000. Manajemen Sumberdaya Manusia. Yogyakarta: BPFEYOGYAKARTA

Musliadi. 2012. Pengaruh Prilaku Kepemimpinan Dan Kompensasi Terhadap Kinerja Karyawan. Skripsi.
Yogyakarta: Universitas Ahmad Dahlan.

Muhith, Setiawan. 2013. Transformational Leadership, Ilustrasi Dibidang Organisasi Pendidikan . Jakarta: Rajagrafindo Persada.

Prahartanto, Adhie. 2012. Dikutip dalam Http://adieprahartanto.blogspot.co.id /2012/08/kumpulan-variabeldimensidan-indikator_28.html?m=1. Diakses 11 Desember 2015.

Pratama, Adhitya, Sri Suryoko dan widiartanto. 2013. Pengaruh Kompensasi, Lingkungan Kerja dan Beban Kerja Terhadap Loyalitas Karyawan melalui Kepuasan Kerja (Studi Kasus Pada Karyawan PT. Berikat Nusantara Persero Jakarta). Jurnal Ekonomi. Diakses pada tanggal 20 Februari 2015. http//www.portalgaruda.com

Ratnasari, Ni Made Maharani Dwi, Kusdi Raharjo dan M. Djudi Makzam. 2013. Pengaruh Insentif Terhadap Loyalitas Karyawan (Studi Pada Karyawan Tetap PT. SIER (Persero), Surabaya). Jurnal Ekonomi.Fakultas Ilmu Administrasi Universitas Brawijaya

Riani, Asri Laksmini. 2011. Budaya Organisasi. Yogyakarta. Graha

Riani, Asri Laksmini. 2013. Manajemen Sumberdaya Manusia Masa Kini. Yogyakarta: Graha Ilmu.

Richard S., Coughlan. 2005. Employee loyalty as adherence to shared moral value, Jurnal of Management Issues 
17.1,Spring, Hal 4 Runtu, Julius. 2014. Indikator Loyalitas Karyawan ( Bahan Diskusi V MSDM II) Diakses dari http://juliusruntu.blogspot.com/2014/ 02/indikator-loyalitaskaryawanbahan.html Pada tanggal 14 September 2015.

Sapaynarta, A. A Made Ossy dan A. A Sagung Kartika Dewi. 2013. Pengaruh Insentif Finansial Dan Lingkungan Kerja Terhadap Loyalitas Karyawan PT. Jasaraharja Putera Cabang Denpasar. Jurnal Ekonomi. Bali. Fakultas Ekonomi Universitas Udayana

Soegandhi, Vannecia Marchelle Dkk. 2013. Pengaruh Kepuasan Kerja Dan Loyalitas Kerja Terhadap Organizational Citizenship Behavior Pada Karyawan PT. Surya Timur Sakti Jatim. Jurnal. Vol. 1,No.1

Sugiyono. 2014. Metodologi Penelitian Kombinasi (mixed Methood). Bandung: Alfabeta

Sujarweni, V. Wiratna. 2007. belajar mudah SPSS untuk Penelitian Skripsi, Tesis, Desertasi, dan Umum. Yogyakarta: Ardana Media.

Widyananto, Roebet. Pengaruh Motifasi dan Lingkungan Kerja Terhadap Prestasi Kerja Karyawan di PT SAI Indonesia Cabang Yogyakarta. Skripsi. Yogyakarta: Universitas Ahmad Dahlan. 